\title{
Analysis of problems during implementation of Lean Manufacturing elements
}

\author{
Manuela Ingaldi ${ }^{1}$, Szymon T. Dziuba ${ }^{2, *}$, and Anna Cierniak-Emerych ${ }^{2}$ \\ ${ }^{1}$ Czestochowa University of Technology, Faculty of Management, Poland \\ ${ }^{2}$ Wroclaw University of Economics, Poland
}

\begin{abstract}
Changes are inherent in activity of any enterprise. Several methods or concepts can be employed to introduce changes. One of the concept which has become popular recently and improves enterprise's functioning is Lean Manufacturing. There are multiple techniques and tools which function within this method. Unfortunately, in the case of any changes, also in the case of implementation of Lean Manufacturing components, one can meet the resistance of employers and a number of technical and organizational problems. The aim of the paper is to collect and analyse information concerning the problems that occur during implementation of the Lean Manufacturing in Polish enterprises. The data were collected by means of a direct questionnaire survey. The results can be a suggestion for the enterprises which are planning to implement the Lean Manufacturing and indicate the problems they should be prepared for in the process.
\end{abstract}

\section{Introduction}

With changing environment and customer requirements, enterprises have to introduce changes also in their structure. The changes can concern many aspects of enterprise activity, concerning both production and non-production aspects.

One of the concepts which is often used in such situations is the Lean Manufacturing (LM). It is not only a slow but continuous process of rationalization of the entire organization but also its relations with the environment. This means ,introduction of substantial changes in terms of activity, property structure and organizational and management methods" [1].

The LM concept allows enterprises to determine value, organize activities that add value with their optimal order, performing the activities without disturbances when the need arises and they are used more and more effectively. Womack and Jones found that LM methodologies are lean because they enable a business to do more with less (less human effort, less equipment, less time, and less space) while always coming closer to meeting customers' exact needs [2-3].

The LM is based on the use of various management methods and techniques, with the most popular including: 5S, Just in Time, Kanban, Kaizen, SMED (Single Minute

\footnotetext{
* Corresponding author: szymon.dziuba@ue.wroc.pl
} 
Exchange of Die), TPM (Total Productive Maintenance), Just in Time, One Piece Flow, work standardization, TQM (Total Quality Management), Poka-Yoke, Hoshin Kanri, VSM (Value Stream Mapping), visual management. This list is not ended [4-5].

Unfortunately, as it is the case with any change, techniques and tools used in the LM are not easy to be implemented. Introduction of nearly every change in enterprises is challenged with employee resistance. Employees can react to changes in two manners: through attitudes, which include emotional internal human inclination to changes and behaviours that manifest themselves in specific activities [6-9].

However, apart from the resistance of the employees, who are often afraid of new duties, increased responsibility for the assignments, introduction of changes also faces several technical and organizational problems connected with the lack of various resources.

Much attention in the literature concerning implementation of the Lean Manufacturing and its elements has been devoted to the outcomes of changes and methods to implement and plan changes. However, the related problems are often neglected [10-16].

The aim of this paper is to indicate problems during and after implementation of the elements of the Lean Manufacturing in Polish enterprises. The examinations were of character of direct questionnaire, with the results based on the answers of the employees from Wrocław and its surroundings in which the LM was implemented. The paper presents only selected results of the analysis.

\section{Metodology}

The examinations concerning the analysis of the problems of implementation of the Lean Manufactuing in Polish enterprises were based on an oral (direct) questionnaire survey. The employees in the enterprises where the mean method was implemented answered to the questions according to the previously prepared form. The interviews with the employees were made in the enterprises they work with but in the absence of direct supervisors. The answers were usually answered by several employees in order to prevent from a direct reactions of the managers to the results. The questionnaire data were collected from both supervisors (one from each enterprise) and low-rank employees.

The results of the research presented in the article are preliminary research, carried out in the period January-March 2018. The research will be continued until December 2018. Firstly the authors sent questions regarding the implementation of Lean Manufacturing and the willingness to participate in the research. The questions were sent to most of the small and medium-sized enterprises from Wrocław and its surroundings.

The survey was performed in 29 small and medium-sized enterprises, with the answers provided by 248 people in total. These were enterprises from the food, electronic and electrical, metal, clothes and chemistry sectors, mostly with Polish capital. These are the results of surveys conducted in enterprises that have implemented selected elements of the Lean Manufacturing and that have agreed to conduct the research as the first, what's more the research was carried out by the end of March 2018. Respondents, who participated in the research, also took part in the implementation of the LM and its elements in the research enterprises. Further research in other enterprises that have agreed to participate in the research should allow to identify the problems of the LM implementation in particular industries.

Implementation of the LM or its elements had started at least 7 years before in 11 enterprises, 2 to 6 years before in 16 enterprises and less than 2 years before in 2 enterprises. 


\section{Results}

The results concerning the major causes of implementation of the LM in the enterprises were first presented (Fig. 1). The employees were allowed to choose more than one answer. None of the respondents checked the „Other” answer.

According to the employees, the most frequent cause of implementation of the LM was to reduce waste in the enterprise (72\%) and improve production efficiency $(69 \%)$. The third indication was popularity of the LM (54\%). These are the major assumptions of the LM.

The requirements of the customers did not exceed $40 \%$, whereas market requirements reached $27 \%$. This means that the decision on the implementation of the LM was made internally in the enterprise and was not forced by the environment.

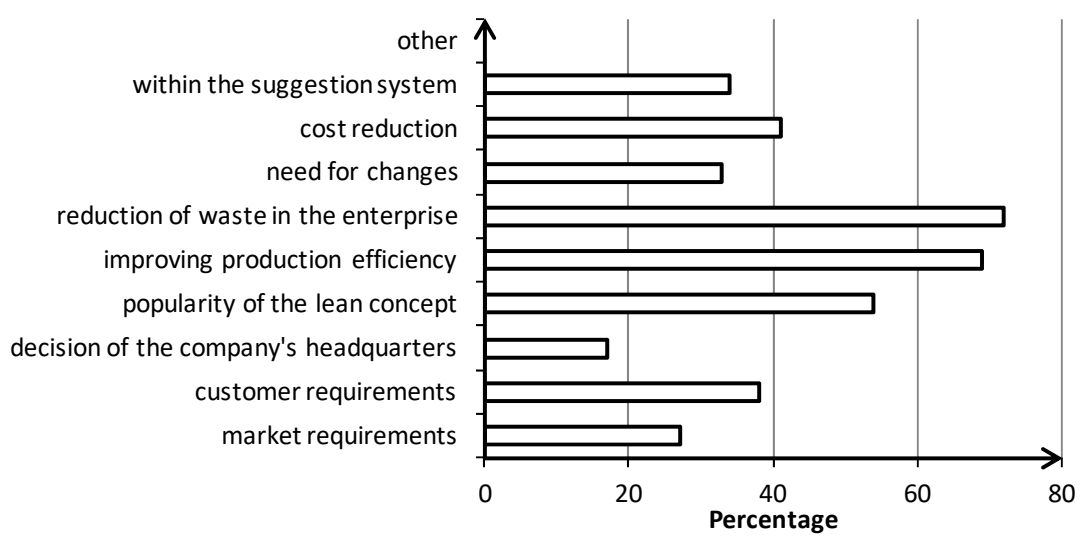

Fig. 1. The major causes of implementation of the Lean Manufacturing or Lean elements in an enterprise [own study].

As with any change, various reactions were observed during the implementation of lean Manufacturing (Fig. 2). In most cases (31\%), the most frequent reaction of employees was resistance to the new. Further reasons was feeling of threat $(25 \%)$ and criticism (17\%). This is the most standard approach of employees to implementation of changes. They are accustomed to what happens in the enterprise and know what they are responsible for and what their assignments are.

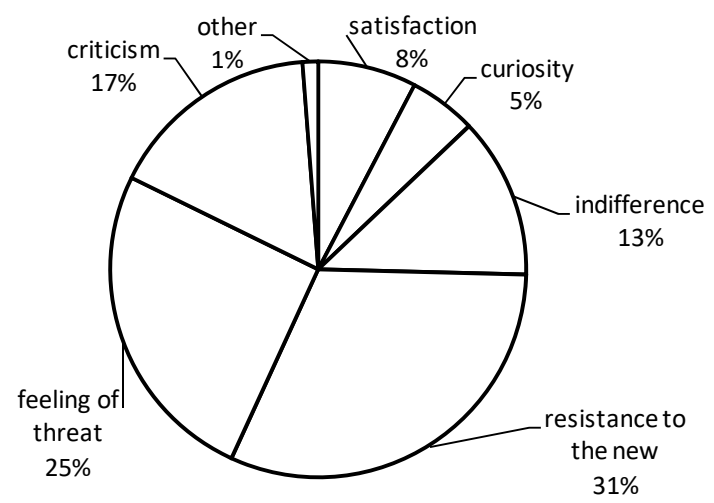

Fig. 2. Main reactions of employees to implementation of the Lean Manufacturing [own study]. 
Changes often involve new duties, the need for modification of previous behaviours and habits and learning. Therefore, it is important that implementation of any Lean elements in the enterprise should be preceded by talking to employees and training which will make them more open to the new and what can happen.

During implementation of the Lean Manufacturing, employees in the enterprises encountered several problems (Tab. 1). Also in this case, the employees could indicate several answers.

The most frequent cause of problems during implementation of the LM was improper communication in the enterprise $(65 \%)$. This is the serious problem since adequate communication between the employees determines the success of the enterprise. Unfortunately, problems with communication are a typical Polish problem in enterprises. Despite the specific organizational structure, the employees do not know who they should turn to with problems and who they should listen to. Information flow is often difficult.

Another important cause of the problems is excessive pressure of the owners $(61 \%)$ with the lack of support of the top managers (57\%). Owners often require impossible things from their employees and give instructions, expect results while they are not willing to help. However, the success of the Lean Manufacturing requires involvement of all employees and the managers should be the role models for other employees.

A substantial problem is reluctance of employees to give up previous privileges (47\%). This is connected with previous components i.e. communication in the enterprise and attitudes of managers.

$43 \%$ of people indicated insufficient amount of training on the Lean Manufacturing. Individual techniques and tools of the LM are not difficult to be used. However, it should be remembered that all employees have higher education level and do not have the most basic knowledge of production engineering. Therefore, employees should be instructed how each instrument works, provided with practical classes and should see the results obtained by other enterprises. This can suggest them how to use these instruments and reduce the resistance or reluctance of employees to changes. Training should be the second stage of the implementation of the LM, after presentation of the causes and expectations of managers concerning implementation of the concept and showing the support for the employees.

Table 1. The main causes of problems during implementation of Lean Manufacturing [own study].

\begin{tabular}{|c|c|}
\hline $\begin{array}{c}\text { The main causes of problems during implementation of Lean } \\
\text { Manufacturing }\end{array}$ & Percentage \\
\hline high pressure of the owners & 61 \\
\hline hurry & 53 \\
\hline no general indications for implementation of Lean Manufacturing & 19 \\
\hline no support of top managers & 57 \\
\hline no financial funds & 29 \\
\hline results only from the standpoint of reduction of organizational costs & 37 \\
\hline inefficient communication in the enterprise & 65 \\
\hline thinking that resources are insufficient & 24 \\
\hline Individual large projects are implemented, without the long-term plan to & 39 \\
\hline implement Lean Manufacturing & 43 \\
\hline insufficient amount of training on Lean Manufacturing & 47 \\
\hline employee's reluctance to give up previous privileges & 1 \\
\hline other & \\
\hline
\end{tabular}


The respondents were also asked about major causes of insufficient effects of implementation of the LM elements in the enterprise studied (Fig. 3). Respondents were allowed to indicate several answers.

It turned out that this was related mainly to the lack of employee's commitment $(73 \%)$, lack of self-discipline (69\%) and return to old habits (67\%). This is connected with answers to the previous question i.e. the lack of adequate communication in the enterprise, the requirement and the lack of support of the managers and insufficient amount of training concerning the Lean Manufacturing. Showing the need for changes and commitment of managers would impact on reduction of the percentage of these causes.

The problem can be connected with another cause i.e. huge rotation of employees $(62 \%)$. This is the problem typical of many Polish enterprises, not only those which implement the Lean Manufacturing. New employees should be trained on e.g. LM and learn about challenges the enterprises have to face and how the Lean enterprises function. This involves additional time and expenses. New employees need some time to become part of team in the enterprise and even more in order to identify with changes that occur in the enterprise.

This is related with poorly developed LM culture, which was directly indicated only by $48 \%$ of the respondents. Building such a culture in the enterprise and, consequently, feeling of association with the enterprise and opportunities for suggesting improvement is the basis for a success of the Lean Manufacturing.

Procedures created within the Lean Manufacturing are too complex and difficult to employees (61\% of the indications). This translates into the lack of commitment and return to old habits. If one does not know how to do something, they do as they can and as they did before. The procedures should be created with the employees the procedure concern. They can help create procedures and give clues about the language that should be used in order for the procedure to be understood by others.

$17 \%$ of the respondents indicated the answer „Other”. However, no additional information was given despite such an opportunity.

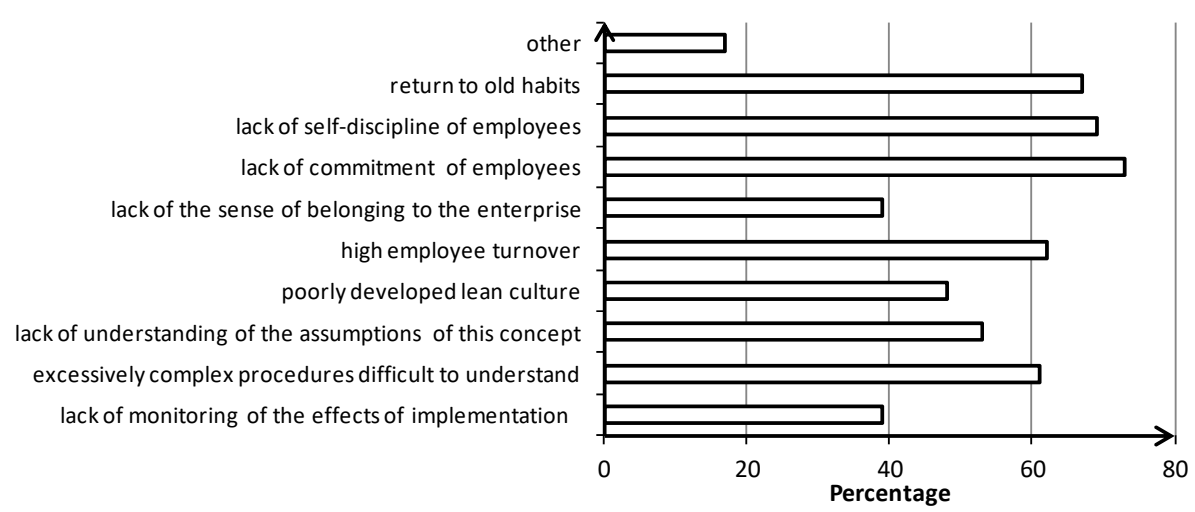

Fig. 3. Main causes of insufficient effects of implementation of Lean Manufacturing [own study].

\section{Summary and conclusion}

The paper presents the results of a direct questionnaire survey which was conducted in Polish enterprises and which concerned the problems encountered during implementation of the Lean Manufacturing and its instruments. The employees indicated several problems with implementation, with the most important being insufficient communication in the 
enterprise, excessive pressure of the owners and lack of support of top managers. The most important causes of insufficient effects of the implementation of the Lean Manufacturing is the lack of commitment of employees, lack of self-discipline and tendencies for returning to old habits.

Everybody is afraid of changes, which is a natural process. It is important that to familiarize with these changes, their course and causes, which will help accept the situation and understand the need for implementation.

Each change can be connected with several problems which are encountered at various stages. The problems should be analysed and their causes should be identified in order to cope with them. It is critical not to give up and to implement changes as they are an important stage of each enterprise.

\section{Reference}

1. J. Lipecki, Ekonomika i Organanizacja Przedssiębiorstw 8, 12-15 (1998)

2. J.P. Womack, D.T. Jones, Odchudzanie firm. Eliminacja marnotrawstwa-kluczem do sukcesu (Centrum Informacji Menedżera, Warszawa, 2001)

3. J.P. Womack, D.T. Jones, D. Roos, Machine that changed the world (Simon and Schuster, New York, 1990)

4. J. Czerska, Doskonalenie strumienia wartości (Difin, Warszawa, 2009)

5. M. Podobiński, Nauki o Zarządzaniu - Management Science, 3(24), 112-122 (2015)

6. M. Nowicka Skowron, R. Ulewicz, 25th International Conference on Metallurgy and Materials (Brno, Czech Rep., 1962-1967, 2016)

7. D. Klimecka-Tatar, Production Engineering Archives, 17, 40-44 (2017)

8. R. Ulewicz, D. Jelonek, M. Mazur, Management And Production Engineering Review, 7, 89-94 (2016)

9. A. Pacana, R. Ulewicz, Polish Journal of Management Studies, 16, 165-174 (2017)

10. S. Gobinath, D. Elangovan, S. Dharmalingam, International Journal of ChemTech Research 8, 44-51 (2015)

11. A.P. Puvanasvaran, M.H.M.A. Megat, S.H. Tang, M.R. Muhamad, A.M.S. Hamouda, American Journal of Applied Sciences, 5, 504-511, (2008)

12. P. Jedynak, Jagiellonian Journal of Management, 1, 51-64 (2015)

13. G.A. Marodin, T.A. Aurin, Journal of Manufacturing Technology Management, 26, 57-79 (2015)

14. R. Ulewicz, J. Selejdak, S. Borkowski, M. Jagusiak-Kocik, 22nd International Conference on Metallurgy and Materials (Brno, Czech Rep., 1926-1931, 2013)

15. M. Nowicka Skowron, R. Ulewicz, 24th International Conference on Metallurgy and Materials (Brno, Czech Rep., 1707-1712, 2015).

16. K. Knop, M. Ingaldi, M. Smilek-Starczynowska, Advances in Manufacturing. (red.) Hamrol A., Ciszak O., Legutko S., Jurczyk M., Reduction of Errors of the Conformity Assessment During the Visual Inspection of Electrical Devices (Springer International Publishing, Cham, 2018) 